Subscriber access provided by Caltech Library

\title{
Article
}

\section{Csp3-Csp3 Bond-Forming Reductive Elimination from Well-Defined Copper(III) Complexes}

Matthew Paeth, Sam B. Tyndall, Liang-Yu Chen, Jia-Cheng Hong, William P. Carson, Xingwu Liu, Xiaodong Sun, Jinjia Liu, Kundi Yang, Elizabeth M. Hale, David

L. Tierney, Bin Liu, Zhi Cao, Mu-Jeng Cheng, William A. Goddard, and Wei Liu

J. Am. Chem. Soc., Just Accepted Manuscript • DOI: 10.1021/jacs.8b12632 • Publication Date (Web): 25 Jan 2019

Downloaded from http://pubs.acs.org on January 25, 2019

\section{Just Accepted}

"Just Accepted" manuscripts have been peer-reviewed and accepted for publication. They are posted online prior to technical editing, formatting for publication and author proofing. The American Chemical Society provides "Just Accepted" as a service to the research community to expedite the dissemination of scientific material as soon as possible after acceptance. "Just Accepted" manuscripts appear in full in PDF format accompanied by an HTML abstract. "Just Accepted" manuscripts have been fully peer reviewed, but should not be considered the official version of record. They are citable by the Digital Object Identifier (DOIB). "Just Accepted" is an optional service offered to authors. Therefore, the "Just Accepted" Web site may not include all articles that will be published in the journal. After a manuscript is technically edited and formatted, it will be removed from the "Just Accepted" Web site and published as an ASAP article. Note that technical editing may introduce minor changes to the manuscript text and/or graphics which could affect content, and all legal disclaimers and ethical guidelines that apply to the journal pertain. ACS cannot be held responsible for errors or consequences arising from the use of information contained in these "Just Accepted" manuscripts. 


\section{INTRODUCTION}

As an inexpensive, earth-abundant and non-toxic metal, copper has found a wide range of applications in homogenous catalysis, allowing for the construction of important pharmaceuticals, materials and commodity chemicals. ${ }^{1-4}$ Highvalent organocopper(III) compounds have long been proposed as key intermediates in many copper-catalyzed reactions, in which the carbon-carbon or carbon-heteroatom bond-forming reductive elimination from $\mathrm{Cu}^{\mathrm{III}}$ species is considered the final product-releasing step. ${ }^{5-12}$ Therefore, significant amounts of work have been conducted to synthesize organocopper(III) complexes and understand their reactivity. ${ }^{13-21}$ However, $\mathrm{Cu}^{\mathrm{III}}$ complexes with well-defined structures remain rather limited and most reported examples were stabilized by rigid macrocyclic chelating ligands or perfluorinated groups, ${ }^{18,22-26}$ few of which provide experimental evidence for reductive elimination of $\mathrm{Cu}^{\mathrm{III}}$ species to form $\mathrm{C}-\mathrm{C}$ or C-heteroatom bonds. ${ }^{27-29}$ Seminal work by Stahl and Ribas have shown that a series of $\mathrm{Cu}^{\mathrm{III}}$-mono-aryl species stabilized by an electrondonating macrocyclic ligand can undergo $\mathrm{C}$-heteroatom bondforming reductive elimination reactions. The $\mathrm{Xi}$ group has recently reported a novel organocopper(III) spiro complex that can undergo intramolecular C-C bond-forming reductive elimination. However, these reported examples require special ligands and/or are limited to specific structures and, as a result, considerable controversy remains over the mechanism of the reductive elimination from $\mathrm{Cu}^{\mathrm{III}}$ species.

Trifluoromethyl groups $\left(\mathrm{CF}_{3}\right)$ have been playing an important role in organocopper(III) chemistry. On one hand, $\mathrm{CF}_{3}$ groups are known to stabilize $\mathrm{Cu}^{\mathrm{III}}$ complexes, probably due to the strong $\mathrm{Cu}^{\mathrm{III}}-\mathrm{CF}_{3}$ sigma bond and thus the high thermal stability. ${ }^{30-32}$ Burton has reported the first crystallographically characterized copper(III) complex, $\left[\mathrm{Cu}^{\mathrm{III}}\left(\mathrm{CF}_{3}\right)_{2}\left(\mathrm{SC}(\mathrm{S}) \mathrm{NEt}_{2}\right)\right]$, in 1989. ${ }^{22}$ Later, $\mathrm{Cu}^{\mathrm{III}}\left(\mathrm{CF}_{3}\right)_{4}^{-}$anion was first synthesized by Neumann ${ }^{33}$ and, very recently, by Grushin using an optimized method. ${ }^{18} \mathrm{Cu}^{\text {III- }}-\mathrm{CF}_{3}$ complexes bearing nitrogen-containing ligands or a methyl group have recently been synthesized by Grushin $^{18}$, Zhang ${ }^{34-36}$ and $\mathrm{Li}^{37}$ On the other hand, the unique properties of $\mathrm{CF}_{3}$ groups in medicinal chemistry ${ }^{38-39}$ have driven the development a large number of copper-promoted $\mathrm{C}-\mathrm{CF}_{3}$ bond-forming reactions. ${ }^{40-49} \mathrm{In}$ some of these reactions, $\mathrm{C}^{-} \mathrm{CF}_{3}$ bond-forming reductive elimination from $\mathrm{Cu}^{\mathrm{III}}$ is indicated as the key step. ${ }^{50-51}$ However, this elementary reductive elimination step remains poorly understood, especially for the 
$\mathrm{Csp}^{3}-\mathrm{CF}_{3}$ bond-forming reductive elimination. Although aryl$\mathrm{CF}_{3}$ bond-forming reductive elimination has been studied on $\mathrm{Pd}^{\mathrm{II} / \mathrm{IV}}, \mathrm{Ni}^{\mathrm{III}}$ and $\mathrm{Au}^{\mathrm{III}}$ complexes, ${ }^{4,}{ }^{52-55} \mathrm{Csp}^{3}-\mathrm{CF}_{3}$ bond-forming reductive elimination from any transition metal complexes with well-defined structures remains essentially unknown. Toste has recently reported a formal $\mathrm{Csp}^{3}-\mathrm{CF}_{3}$ reductive elimination from $\mathrm{Au}^{\mathrm{III}}$ via a fluoride-rebound mechanism. ${ }^{56}$ This work represents the first net $\mathrm{Csp}^{3}-\mathrm{CF}_{3}$ bond-forming reaction from structurallydefined complexes, although the $\mathrm{C}-\mathrm{C}$ bond is formed via the alkyl-migration pathway. Li's group and our group have shown that a $\left[\mathrm{Cu}^{\mathrm{I}} \mathrm{CF}_{3}\right]$ species generated possibly in situ via the reductive elimination of a $\mathrm{Cu}^{\mathrm{III}}$ complex promotes trifluoromethylation of alkyl radicals. ${ }^{37,49}$ However, the reductive elimination is only limited to a methyl-containing copper(III) complex.

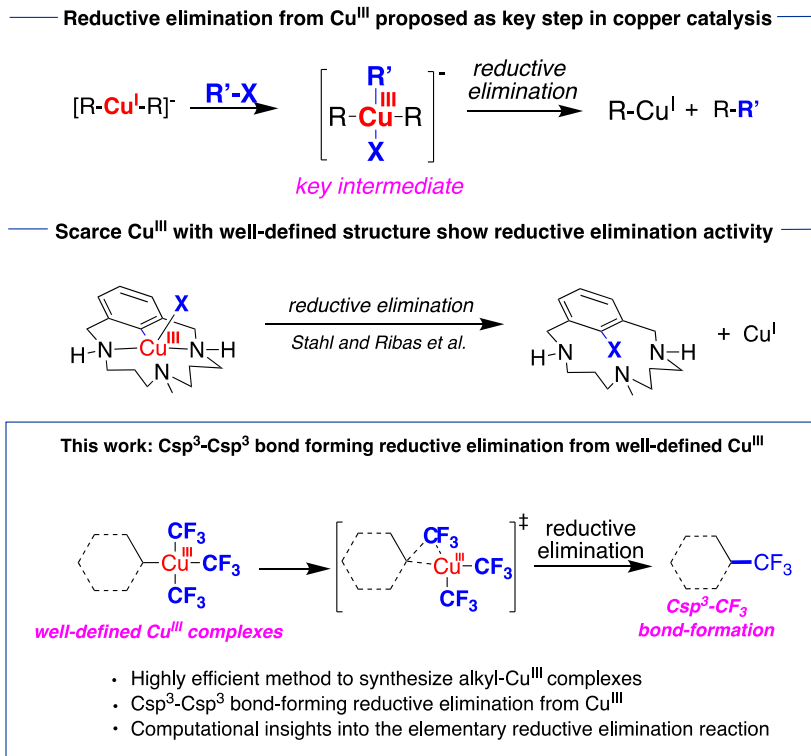

Due to the importance of $\mathrm{Cu}^{\mathrm{III}}$ in copper catalysis and the lack of isolable yet reactive $\mathrm{Cu}^{\mathrm{III}}$ complexes, development of general methods for the synthesis of structurally-defined organocopper(III) complexes and study their ability for C-C bond-forming reductive elimination will be vital in the progression of $\mathrm{Cu}$-based organometallic chemistry and catalysis. Furthermore, understanding the $\mathrm{Csp}^{3}-\mathrm{CF}_{3}$ bondforming reductive elimination from high-valent metal complexes will also help the development of novel alkyl trifluoromethylation reactions, which are highly important in medicinal chemistry but remain less-explored compared to well-developed aryl trifluoromethylation reactions. In this article, we report the design, synthesis and reductive elimination activity of a novel class of organometallic copper (III) complexes, [alkyl- $\left.\mathrm{Cu}^{\mathrm{III}}-\left(\mathrm{CF}_{3}\right)_{3}\right]^{-}$, with diverse functional groups. The molecular structures of these complexes have been determined by NMR, MS and X-ray crystal structure. More importantly, these complexes undergo $\mathrm{Csp}^{3}-\mathrm{CF}_{3}$ reductive elimination, forming the corresponding alkyl- $\mathrm{CF}_{3}$ products with excellent yields. These copper(III) complexes, for the first time, allow for the study of $\mathrm{Csp}^{3}-\mathrm{Csp}^{3}$ bond-forming reductive elimination on well-defined copper(III) complexes.

\section{RESULTS AND DISCUSSION}

Synthesis and characterizations of $\left[(\text { alkyl }) \mathrm{Cu}^{\mathrm{III}}\left(\mathrm{CF}_{3}\right)_{3}\right]^{-}$ complexes. We reason that a $\left[\mathrm{Cu}^{\mathrm{III}}-\mathrm{CF}_{3}\right]$ complex containing a replaceable ligand could serve as the precursor for the [alkyl-
$\mathrm{Cu}^{\mathrm{III}}-\mathrm{CF}_{3}$ ] complexes. Thus, we synthesized complex $\mathbf{1}$, $\left[\mathrm{PyCu}{ }^{\mathrm{III}}\left(\mathrm{CF}_{3}\right)_{3}\right]$ ( $\mathrm{Py}=$ pyridine), following the literature method. ${ }^{36}$ Although the structure of compound 1 with a DMF ligand (1-DMF) has been reported, the crystal of compound 1 without additional ligands can be obtained by the slow diffusion of pentane to a DCM solution of $\mathbf{1}$. In contrast to the square pyramidal structure of 1-DMF, crystal structure of $\mathbf{1}$ adopts the square-planar geometry (Fig. S1), with the pyridine ring perpendicular to the plane of copper.

Treating 1 with 1 equiv. of various alkyl zinc reagents at room temperature affords the corresponding $\left[(\right.$ alky $\left.) \mathrm{Cu}^{\mathrm{III}}\left(\mathrm{CF}_{3}\right)_{3}\right]$ species within 5 mins in nearly quantitative yields (Fig. 1). Compound 1 displays two ${ }^{19} \mathrm{~F}-\mathrm{NMR}$ signals at $38 \mathrm{ppm}$ and 24 ppm, while $\left[(\text { alky }) \mathrm{Cu}^{\mathrm{III}}\left(\mathrm{CF}_{3}\right)_{3}\right]^{-}$complexes show two new peaks at $\sim-35 \mathrm{ppm}$ and $-36 \mathrm{ppm}$, with an integral of 1:2, consistent with a planar structure with two inequivalent $\mathrm{CF}_{3}$ groups. In addition, [(alky) $\left.\mathrm{Cu}^{\mathrm{III}}\left(\mathrm{CF}_{3}\right)_{3}\right]^{-}$display well-resolved ${ }^{1} \mathrm{H}-\mathrm{NMR}$ spectrum, consistent with a low spin $\mathrm{d}^{8}$ configuration of $\mathrm{Cu}^{\mathrm{III}}$. For example, the proton of the $\mathrm{CH}_{2}$ groups connecting to copper in 1a and 1d displays chemical shifts at 3.6 and $2.4 \mathrm{ppm}$, respectively, indicating the moderate electron-deficiency nature of the $\mathrm{Cu}^{\text {III }}$ center. The moderate stability of these $\left[(\text { alky }) \mathrm{Cu}^{\mathrm{III}}\left(\mathrm{CF}_{3}\right)_{3}\right]^{-}$(hours at r.t. and weeks at $-20^{\circ} \mathrm{C}$ ) allowed us to confirm their composition using high-resolution electrospray ionization mass spectrometry (HR ESI-MS). Gratifyingly, these $\left[(\text { alky }) \mathrm{Cu}^{\mathrm{III}}\left(\mathrm{CF}_{3}\right)_{3}\right]^{-}$anions can be easily detected at negative mode with normal ESI parameters (See SI for details). For example, compound 1a and 1d show peaks at $\mathrm{m} / \mathrm{z}=360.9695$ and 326.9854, respectively, consistent with the formation of $\left[(\text { benzyl }) \mathrm{Cu}^{\mathrm{III}}\left(\mathrm{CF}_{3}\right)_{3}\right]^{-}$and $\left[(n \mathrm{Bu}) \mathrm{Cu}^{\mathrm{III}}\left(\mathrm{CF}_{3}\right)_{3}\right]^{-}$anions.
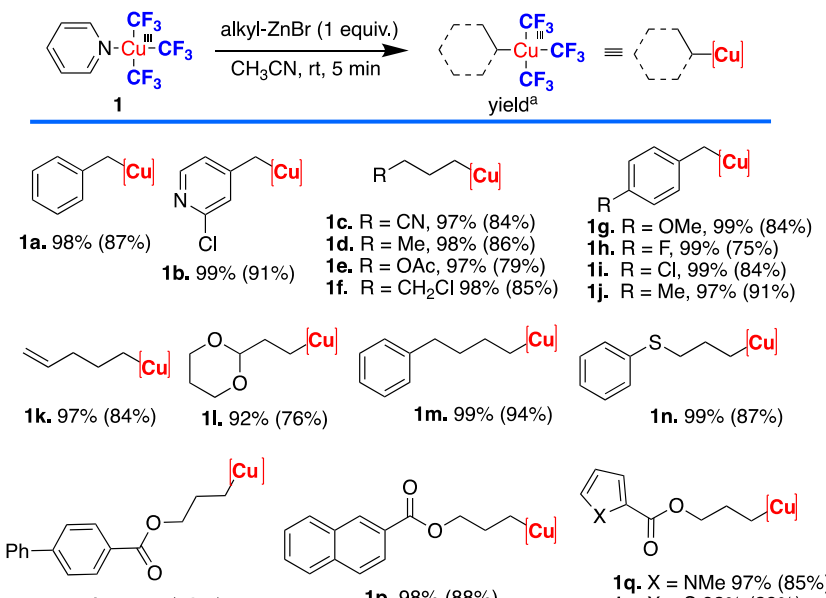
10. $99 \%(92 \%)$ 1p. $98 \%(88 \%)$ 1q. $X=N M e 97 \%(85 \%)$ 1r. $X=S 98 \%(89 \%)$<smiles>[X]c1cc2ccccc2cc1C(=O)OCCCC</smiles><smiles>OCCOc1cccn1CCCCl</smiles>
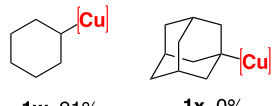

1t. $X=\mathrm{NMe} 99 \%(87 \%)$ 1u. $X=098 \%(79 \%)$

Figure 1. Synthesis of $\left[(\text { alkyl }) \mathrm{Cu}^{\mathrm{III}}\left(\mathrm{CF}_{3}\right)_{3}\right]^{-}$species. Yields determined by ${ }^{19} \mathrm{~F}-\mathrm{NMR}$ using 1-fluoro-3-nitrobenzene as the internal standard. Isolate yields as $\left[\mathrm{nBu}_{4} \mathrm{~N}\right]^{+}$salts are included in parenthesis.

This transmetallation protocol allows for the synthesis of a large variety of $\left[(\text { alkyl }) \mathrm{Cu}^{\mathrm{III}}\left(\mathrm{CF}_{3}\right)_{3}\right]^{-}$complexes (Fig. 1). Common functional groups, including alkenyl, nitrile, acetal, thiol ether etc. are compatible with the reaction conditions. In 
addition, molecules containing different heterocycles are also tolerated under this condition. This method works well for the construction of both primary and secondary alkyl- $\mathrm{Cu}^{\text {III }}$ species, but our attempts to the synthesis of tertiary alkyl-Cu $\mathrm{Cu}^{\mathrm{III}}$ species (1x) were not successful, probably due to slow transmetallation of 1 with the bulky adamantyl zinc reagent as well as the instability of the resulting $\mathrm{Cu}^{\mathrm{III}}$ species. Nevertheless, we were able to detect the transient formation of $\mathbf{1} \mathbf{x}$ using HR ESI-MS (Fig. S2).

The structures of these $\mathrm{Cu}^{\text {III }}$ complexes were further confirmed by single crystal X-ray diffraction. One equivalent of tetrabutylammonium bromide $\left(n-\mathrm{Bu}_{4} \mathrm{NBr}\right)$ was added to the $\mathrm{Cu}^{\mathrm{III}}$ solutions to form the corresponding $\left[n-\mathrm{Bu}_{4} \mathrm{~N}\right]^{+}$salts, which can be purified by silica gel column chromatography at $-78^{\circ} \mathrm{C}$. The crystals of $1 \mathbf{a}-1 \mathbf{c}$ as $\left[n-\mathrm{Bu}_{4} \mathrm{~N}\right]^{+}$salts were grown by the slow diffusion of pentane into a methylene chloride solution at -20 ${ }^{\circ} \mathrm{C}$ over a week. 1a-1c display square planar geometry with slight distortion (Fig. 2). The bond lengths of $\mathrm{Cu}^{\mathrm{IIII}}-\mathrm{CF}_{3}$ bonds trans to the alkyl group are in a range of $1.979-1.987 \AA$, slightly longer than that of $\mathrm{Cu}^{\mathrm{III}}-\mathrm{CF}_{3}$ bonds cis to the alkyl groups ( $\mathrm{Cu}-\mathrm{C} 1.944-1.961 \AA)$. The bond lengths of $\mathrm{Cu}-\mathrm{C}_{\text {alky }}$ bonds are longer in 1a and 1b (1.997(3) $\AA$ and 1.988(3) $\AA$ ), which contain benzyl groups, than that in 1c (1.956(3) A). In addition, on the contrary to the perpendicular geometry of pyridine and copper plane in compound $\mathbf{1}$, the aryl rings in compounds $1 \mathbf{a}$ and $\mathbf{1 b}$ form $\mathrm{V}$-shape geometry with the copper plane with a dihedral angle of $\sim 105^{\circ}$. Well-defined organocopper(III) complexes are rare and it is noteworthy that compounds shown here represent the only isolated organocopper(III) complexes containing alkyl groups other than a simple methyl group.
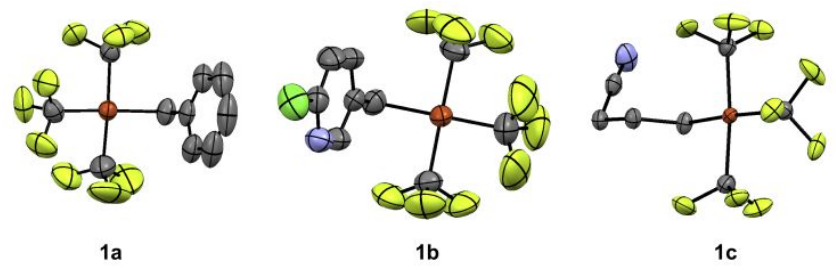

Figure 2. X-ray crystal structures of complexes $\mathbf{1 a}, \mathbf{1 b}$ and $\mathbf{1 c}$ as $\left[n \mathrm{Bu}_{4} \mathrm{~N}\right]^{+}$salts. Oak Ridge thermal ellipsoid plot (ORTEP) drawing with atoms at $50 \%$ probability; hydrogen atoms and $\left[n \mathrm{Bu}_{4} \mathrm{~N}\right]^{+}$ counter cations omitted for clarity.

Reductive elimination activity of $\left[(\text { alkyl }) \mathrm{Cu}^{\mathrm{III}}\left(\mathrm{CF}_{3}\right)_{3}\right]^{-}$ complexes. With these $\mathrm{Cu}^{\mathrm{III}}$ complexes in hand, we then studied their reductive elimination reactivity. At elevated temperature $\left(55{ }^{\circ} \mathrm{C}\right)$, these complexes undergo reductive elimination, leading to the consumption of starting $\mathrm{Cu}^{\mathrm{III}}$ and concomitant formation alkyl- $\mathrm{CF}_{3}$ products with varying yields (Fig. 3). We followed the reductive elimination of $\mathbf{1 d}$ in a temperature range of $45-65^{\circ} \mathrm{C}$ by ${ }^{19} \mathrm{~F}-\mathrm{NMR}$ (Fig. 4A and Fig. S3). At all temperature, reductive elimination of $\mathbf{1 d}$ follows a first-order rate law (Fig. 4B) forming $\mathbf{2 d}$ as the major products with yield ranging from $85-89 \%$. The $\mathrm{Cu}^{\mathrm{I}}$ byproducts of the reactions are $\mathrm{Cu}\left(\mathrm{CF}_{3}\right)_{2}^{-}$, which has been detected by ESI-MS (Fig. S4). We also observed the formation of $\mathrm{Cu}^{\mathrm{III}}\left(\mathrm{CF}_{3}\right)_{4}$, presumably formed via aerobic oxidation of the $\mathrm{Cu}^{\mathrm{I}}$ complexes. The observed firstorder rates for the reductive elimination of $\mathbf{1 d}$ is $k_{65}=1.04 \times$ $10^{-3} \mathrm{~s}^{-1}$ at $65^{\circ} \mathrm{C}$ and $k_{45}=1.45 \times 10^{-4} \mathrm{~s}^{-1}$ at $45^{\circ} \mathrm{C}$, respectively. Eyring plot analysis of the reductive elimination rate at different temperature reveals that reductive elimination of $\mathbf{1 d}$ proceeded with activation enthalpy of $20.3 \mathrm{kcal} / \mathrm{mol}$ and activation entropy of -12.4 e.u. (Fig. 4C), comparable to the reductive elimination of aryl-Pd ${ }^{\mathrm{II}}-\mathrm{CF}_{3}$ complexes reported by Buchwald. ${ }^{57}$

Reductive elimination of $\mathrm{Cu}^{\mathrm{III}}$ complexes bearing benzyl groups (1a, 1g-1j) affords the corresponding trifluoromethylated products in moderate yields $(32-62 \%)$. Analysis of the crude reaction mixtures by GC/MS reveals that dimerized products (bibenzyl) were formed. In addition, when the reductive elimination reactions were conducted under air, benzyl alcohol and benzaldehyde were also formed, while the yields of trifluoromethylated products were not affected. These results suggest that the homolytic cleavage of the $\mathrm{Cu}^{\mathrm{III}}$-benzyl bonds to form benzylic radicals competes with the reductive elimination pathway. As expected, homolytic cleavage of $\mathrm{Cu}^{\mathrm{III}}$ complexes leads to the formation of $\left[\mathrm{Cu}^{\mathrm{II}}\left(\mathrm{CF}_{3}\right)_{3}\right]^{-}$, which has been detected by ESI-MS (Fig. S5) and EPR (Fig. S6). Moreover, studying the reductive elimination of $\mathbf{1 a}$ and $\mathbf{1 g} \mathbf{\mathbf { 1 }} \mathbf{j}$ reveals that reductive elimination generally proceeds faster with electron-donating substituents on the para position of the phenyl ring. A Hammet plot of $\log \left(\mathrm{k}_{\mathrm{obs}} / \mathrm{k}_{\mathrm{obs}(\mathrm{H})}\right) \quad\left(\mathrm{k}_{\mathrm{obs}}\right.$ are calculated using initial rates for the formation of trifluoromethylated products) $v s \sigma_{\text {para }}$ yields a $\rho$ value of -0.602 and a modest correlation $\left(R^{2}=0.840\right)$ (Fig. S7), suggesting that alkyl groups act as the nucleophilic partners in C-C bond formation. The yields of bibenzyl products derived from radical dimerization decreased with electron-donating substituents on the para position. Furthermore, the $\mathrm{Cu}^{\mathrm{III}}$ complex bearing a secondary alkyl group, $\mathbf{1 w}$, is much more reactive toward reductive elimination than its primary analogues. More than $95 \% 1 \mathrm{w}$ reductively eliminates within 5 minutes at $55{ }^{\circ} \mathrm{C}$. At $25^{\circ}, 1 \mathrm{w}$ can also reductively eliminates, forming $2 \mathrm{w}$ with a firstorder rate constant $k_{o b s}=2.7 \times 10^{-3} \mathrm{~s}^{-1}$. (Fig. S8)
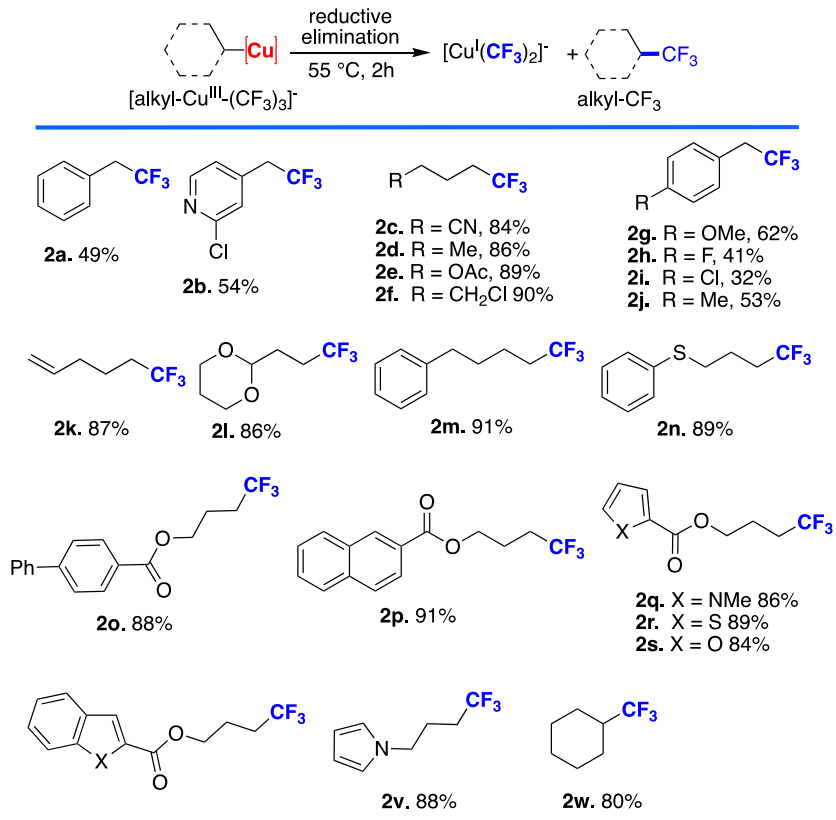

2t. $X=\mathrm{NMe} 83 \%$

2u. $X=086 \%$

Figure 3. Reductive elimination of $\left[(\text { alkyl }) \mathrm{Cu}^{\mathrm{III}}(\mathrm{CF})_{3}\right]^{-}$affords the corresponding alkyl- $\mathrm{CF}_{3}$ products. Reductive elimination reactions were conducted in $\mathrm{CD}_{3} \mathrm{CN}$ at $55^{\circ} \mathrm{C}$; Yield determined by ${ }^{19} \mathrm{~F}-\mathrm{NMR}$ using 1-fluoro-3-nitrobenzene as the internal standard.

Given the mild conditions for both the transmetallation and reductive elimination steps, this procedure allows for the late- 
stage trifluoromethylation of complex organozinc reagents (Fig. 5). We synthesized the organozinc derivatives of five bioactive molecules, including estrone, gemfibrozil, Vitamin E,

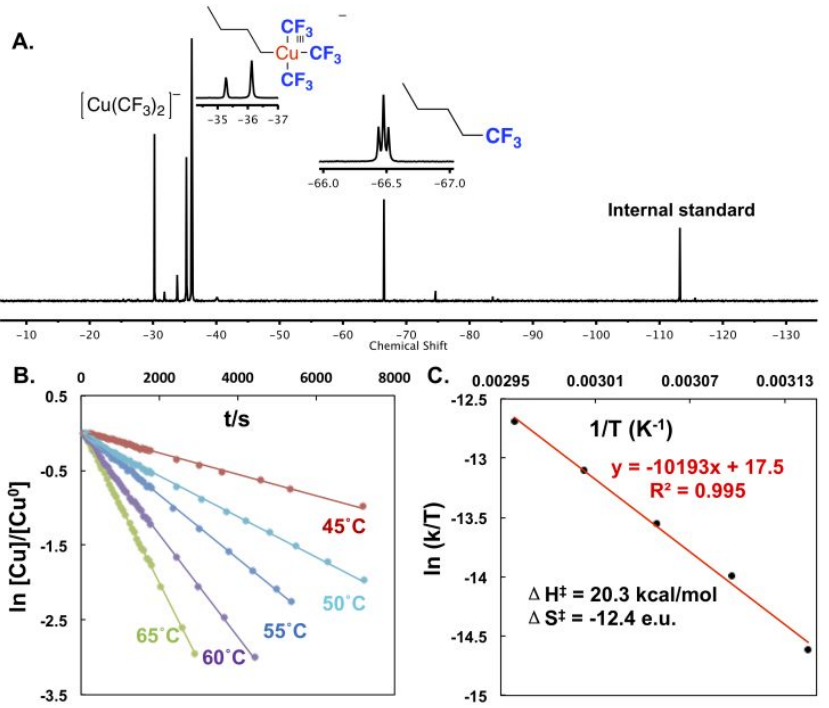

Figure 4. Kinetic studies of the reductive elimination of compound $\left[n \mathrm{Bu}_{4} \mathrm{~N}\right]-\mathbf{1 d} . \mathbf{A}$. Representative ${ }^{19} \mathrm{~F}-\mathrm{NMR}$ spectra of the reductive elimination of $\left[n \mathrm{Bu}_{4} \mathrm{~N}\right]-\mathbf{1 d} ; \mathbf{B}$. First-order plot of reductive elimination of $\left[n \mathrm{Bu}_{4} \mathrm{~N}\right]-\mathbf{1 d}$ at different temperature; C. Erying Plot analysis of the reductive elimination of $\left[n \mathrm{Bu}_{4} \mathrm{~N}\right]-\mathbf{1 d}$.

indomethacin and thalidomide. Upon treating 1 with these organozinc reagents at room temperature, a new set of ${ }^{19} \mathrm{~F}-\mathrm{NMR}$ peaks appeared consistent with the formation of the $\left[(\text { alkyl }) \mathrm{Cu}\left(\mathrm{CF}_{3}\right)_{3}\right]^{-}$species. Heating the solutions of $\mathrm{Cu}^{\mathrm{III}}$ at 55 ${ }^{\circ} \mathrm{C}$ for 2 hours afforded the corresponding trifluoromethylated products in excellent yields. Although trifluoromethylation of alkyl halides have been reported, ${ }^{58-59}$ our procedure allows for the late-stage incorporation of $\mathrm{CF}_{3}$ into complex molecules within a short amount of time and with excellent yields.

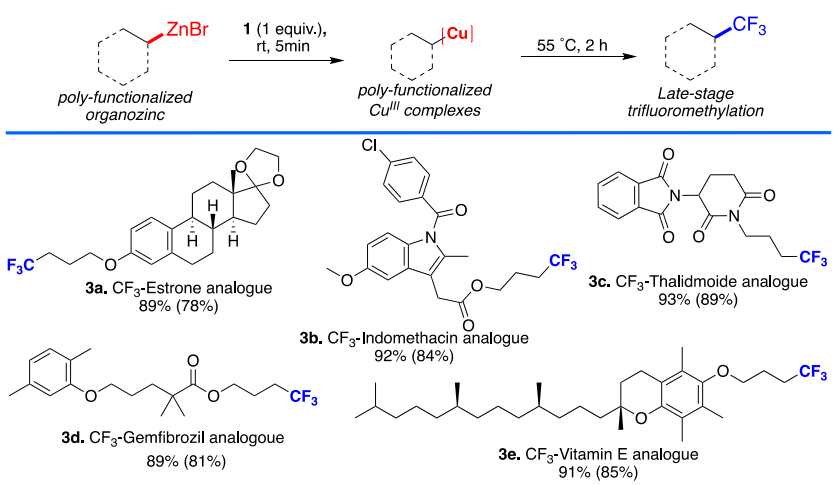

Figure 5. Late-stage trifluoromethylation of highly-functionalized organozinc reagents. Yields determined by ${ }^{19} \mathrm{~F}-\mathrm{NMR}$ using 1fluoro-3-nitrobenzene as the internal standard. Isolated yields are listed in parenthesis.

DFT calculations of the reductive elimination reactions. To gain more insights into this $\mathrm{Csp}^{3}-\mathrm{CF}_{3}$ bond-forming reductive elimination, we performed DFT calculations at the B3LYP level combined with Poisson-Boltzmann continuum solvation to probe the mechanism of this elementary reaction (full details in SI). Based on literature precedents and our experimental results, four pathways were considered (Fig. 6). In Path A, reductive elimination occurs directly on the $\left[(\text { alkyl }) \mathrm{Cu}\left(\mathrm{CF}_{3}\right)_{3}\right]^{-}$species, whereas, in Path $\mathbf{B}$, homolytic cleavage of the $\mathrm{Cu}$-alkyl bond takes place first to generate an alkyl radical which then rebounds to one of the copper-bounded $\mathrm{CF}_{3}$. In Path $\mathbf{C}, \mathrm{a} \mathrm{CF}_{3}$ anion dissociates and then the reductive elimination occurs on the neutral intermediate. Finally, considering the fluoride-rebound mechanism for $\mathrm{C}-\mathrm{CF}_{3}$ bond formation, recently discovered by Toste, ${ }^{56}$ we proposed Path D which involves fluoride dissociation, migratory insertion and C$F$ reductive elimination to achieve net $\mathrm{C}-\mathrm{CF}_{3}$ bond formation.

The energetics of these four pathways for the reductive elimination of 1d are shown in Fig. 6. Although Path D is involved in Toste's $\mathrm{Au}^{\mathrm{III}}$ reductive elimination in the presence of a borane catalyst, ${ }^{56}$ this pathway is not likely involved in our system due to the high energy of the difluorocarbene intermediate formed in the absence of a catalyst (estimated to be $39.1 \mathrm{kcal} / \mathrm{mol}$ ). Likewise, the dissociation of a trifluoromethyl anion in Path $\mathbf{C}$ leads to the formation of a high energy neutral intermediate $(\Delta \mathrm{H}=31.3 \mathrm{kcal} / \mathrm{mol})$. In Path $\mathbf{B}$, we find that the homolytic dissociation of $n$-butyl is barrierless with $\Delta H=21.6 \mathrm{kcal} / \mathrm{mol}$, in which case there is no free $n$-butyl radical available to recombine with a copper-bounded $\mathrm{CF}_{3}$ to form the target product. We assign the concerted alkyl-CF bond-forming pathway (Path $A$ ) as the mechanism. This has the lowest predicted activation enthalpy $\left(\Delta \mathrm{H}^{*}=21.4 \mathrm{kcal} / \mathrm{mol}\right)$, in excellent agreement with the experimental result $\left(\Delta \mathrm{H}^{*}=20.3\right.$ $\mathrm{kcal} / \mathrm{mol}$ ) from the Eyring analysis. As shown by Low and Goddard, reductive coupling of such $\mathrm{Csp}^{3}-\mathrm{Csp}^{3}$ bonds has a high barrier unless the reaction is made very exothermic. ${ }^{60}$ The reaction in path $\mathbf{A}$, is very exothermic $(\Delta \mathrm{H}=-57.9 \mathrm{kcal} / \mathrm{mol})$ and hence is expected to yield a low barrier for the concerted reaction as observed from both theory and experiment. Moreover, the calculated reductive elimination activation energy for $\mathbf{1 w}$ is lower $\left(\Delta \mathrm{H}^{*}=20.0 \mathrm{kcal} / \mathrm{mol}\right)$ than that of $\mathbf{1 d}$, consistent with its faster reductive elimination rate.

$$
\text { D. }
$$

Figure 6. Reaction coordinate of reductive elimination of $\mathbf{1 d}$ and 1a (in parentheses) via four different pathways. The numbers in bold style are $\mathrm{H}^{\dagger} \mathrm{s}$, whereas those in plain style are $\Delta \mathrm{Hs}$.

Given the formation of free radicals observed in benzylcontaining $\mathrm{Cu}^{\mathrm{III}}$ species, we also calculated activation energy for the reductive elimination of $\mathbf{1 a}$ via Path $\mathbf{A}$ and $\mathbf{B}$. Interestingly, the homolytic dissociation of $\mathbf{1 a}$ has a lower activation energy $(\mathrm{H} / \Delta \mathrm{H}=12.6 / 12.5 \mathrm{kcal} / \mathrm{mol})$ than that of direct reductive elimination pathway $\left(H^{\ddagger} / \Delta H=19.7 /-53.6\right.$ $\mathrm{kcal} / \mathrm{mol}$ ), consistent with our experimental results that benzyl radicals are formed. In addition, the activation energy of the reversible reaction, in which the generated benzyl radical recombines with the $\mathrm{Cu}^{\mathrm{II}}$ intermediate reforming compound $\mathbf{1 a}$, 
is only $0.1 \mathrm{kcal} / \mathrm{mol}$. This suggests that a fast equilibrium might exist between 1a and the radical pair. The direct transfer of the $\mathrm{CF}_{3}$ group to the benzyl radical is unlikely as indicated by the high activation energy $\left(\mathrm{H}^{\ddagger} / \Delta \mathrm{H}=41.1 /-66.1 \mathrm{kcal} / \mathrm{mol}\right)$. Moreover, our calculation results have shown that the activation energy of direct reductive elimination decreases with electrondonating groups at the para positions of the phenyl rings; $\mathrm{H}^{*}$ decreases from $21.1 \mathrm{kcal} / \mathrm{mol}$ for $1 \mathbf{i}$ to $20.0 \mathrm{kcal} / \mathrm{mol}$ for $\mathbf{1 h}, 19.7$ $\mathrm{kcal} / \mathrm{mol}$ for $1 \mathrm{a}$, and $17.7 \mathrm{kcal} / \mathrm{mol}$ for $1 \mathrm{~g}$. In addition, the activation energy of radical dissociation (Path B) increases with electron-donating group at the para-position (12.6 $\mathrm{kcal} / \mathrm{mol}$ for $\mathbf{1 a}$ and $13.0 \mathrm{kcal} / \mathrm{mol}$ for $\mathbf{1 g}$ ). These calculation results are consistent with our experimental observations that the formation of benzyl radicals competes with the direct reductive elimination of benzyl-containing $\mathrm{Cu}^{\mathrm{III}}$ species and that the formation radical-derived products decreases with electron-donating substituents on the phenyl rings. Finally, through natural bond orbital (NBO) analysis, ${ }^{61}$ we have found that the NBO charge on $\mathrm{Cu}$ decreases from $0.84 \mathrm{e}$ in the reactant, to $0.71 \mathrm{e}$ in the transition state, and finally to $0.35 \mathrm{e}$ in the product, demonstrating that this is indeed a reductive elimination process.

\section{CONCLUSIONS}

To conclude, we have reported a highly efficient procedure to the synthesis of novel [alkyl- $\left.\mathrm{Cu}^{\mathrm{III}}\left(\mathrm{CF}_{3}\right)_{3}\right]^{-}$complexes, the structures of which have been well-characterized. The organocopper(III) molecules reported here represent the first class of organocopper(III) complexes containing complicated alkyl groups. These high-valent organocopper (III) species undergo reductive elimination to form the corresponding alkyl$\mathrm{CF}_{3}$ compounds and $\left[\mathrm{Cu}^{\mathrm{I}}(\mathrm{CF})_{3}\right]_{2}{ }^{-}$via a concerted pathway. We anticipate that this procedure could help to elucidate the structure and reactivity of other important, yet elusive $\mathrm{Cu}^{\mathrm{III}}$ complexes and that the insights we learned from this reductive elimination reaction will guide the development of novel $\mathrm{Cu}$ catalyzed $\mathrm{C}-\mathrm{C}$ bond-forming reactions. This work on $\mathrm{Csp}^{3}-\mathrm{CF}_{3}$ bond-forming reductive elimination from $\mathrm{Cu}^{\mathrm{III}}$ species indicates a possible catalytic oxidative pathway for trifluoromethylation in which an alkyl- $\mathrm{Cu}^{\mathrm{III}}-\mathrm{CF}_{3}$ intermediate is generated in situ via chemical oxidation, which reductively eliminates to form the $\mathrm{CF}_{3}$ products and regenerate $\mathrm{Cu}^{\mathrm{I}}$ complexes. These research is currently ongoing in our laboratory.

\section{ASSOCIATED CONTENT}

\section{Supporting Information}

Supplementary figures, characterizations of new compounds, computational details and crystal structures. This material is available free of charge on the ACS Publications website.

\section{AUTHOR INFORMATION}

\section{Corresponding Author}

* caozhi@sxicc.ac.cn

*wag@caltech.edu; ORCID:0000-0003-0097-5716

*wei.liu@miamioh.edu; ORCID: 0000-0001-6249-3179

\section{ACKNOWLEDGMENT}

W.L. thanks Miami University for the start-up funding. L.Y.C, J.C.H, and M.J.C acknowledge financial support from the Ministry of Science and Technology of the Republic of China under grant no. MOST 107-2113-M-006-008-MY2.We also thank Dr. Theresa Ramelot for the assistance of HR-ESI and Prof. John
Rakovan for the assistance of X-ray crystal diffraction. W.A.G. acknowledge financial support from NSF (NSF CBET 1512759)

\section{REFERENCES}

1. Allen, S. E.; Walvoord, R. R.; Padilla-Salinas, R.; Kozlowski, M. C., Aerobic Copper-Catalyzed Organic Reactions. Chem. Rev. 2013, 113 (8), 6234-6458.

2. Hickman, A. J.; Sanford, M. S., High-valent organometallic copper and palladium in catalysis. Nature 2012, 484, 177.

3. Evano, G.; Blanchard, N.; Toumi, M., Copper-Mediated Coupling Reactions and Their Applications in Natural Products and Designed Biomolecules Synthesis. Chem. Rev. 2008, 108 (8), 30543131.

4. $\quad$ Bakhmutov, V. I.; Bozoglian, F.; Gómez, K.; González, G.; Grushin, V. V.; Macgregor, S. A.; Martin, E.; Miloserdov, F. M.; Novikov, M. A.; Panetier, J. A.; Romashov, L. V., CF3-Ph Reductive Elimination from [(Xantphos) $\mathrm{Pd}(\mathrm{CF} 3)(\mathrm{Ph})]$. Organometallics 2012, 31 (4), 1315-1328.

5. Beletskaya, I. P.; Cheprakov, A. V., Copper in crosscoupling reactions: The post-Ullmann chemistry. Coord. Chem. Rev. 2004, 248 (21), 2337-2364.

6. Monnier, F.; Taillefer, M., Catalytic C-C, C-N, and C-O Ullmann-Type Coupling Reactions. Angew. Chem. Int. Ed. 2009, 48 (38), 6954-6971.

7. Sperotto, E.; van Klink, G. P. M.; van Koten, G.; de Vries, J. G., The mechanism of the modified Ullmann reaction. Dal. Trans. 2010, 39 (43), 10338-10351.

8. $\quad$ Nakamura, S.; Nakagawa, R.; Watanabe, Y.; Toru, T., Enantioselective Reactions of Configurationally Unstable $\alpha$ Thiobenzyllithium Compounds. Angew. Chem. Int. Ed. 2000, 39 (2), 353-355.

9. Santo, R.; Miyamoto, R.; Tanaka, R.; Nishioka, T.; Sato, K.; Toyota, K.; Obata, M.; Yano, S.; Kinoshita, I.; Ichimura, A.; Takui, T., Diamagnetic-Paramagnetic Conversion of Tris(2pyridylthio)methylcopper(III) through a Structural Change from Trigonal Bipyramidal to Octahedral. Angew. Chem. Int. Ed. 2006, 45 (45), 7611-7614.

10. Cohen, T.; Wood, J.; Dietz, A. G., Organocopper intermediates in the exchange reaction of aryl halides with salts of copper(I). The possible role of copper(III). Tetrahedron Lett. 1974, 15 (40), 3555-3558.

11. Dorigo, A. E.; Wanner, J.; von Ragué Schleyer, P., Computational Evidence for the Existence of CuIII Intermediates in Addition and Substitution Reactions with Dialkylcuprates. Angew. Chem. Int. Ed. 1995, 34 (4), 476-478.

12. Kainz, Q. M.; Matier, C. D.; Bartoszewicz, A.; Zultanski, S. L.; Peters, J. C.; Fu, G. C., Asymmetric copper-catalyzed C-N cross-couplings induced by visible light. Science 2016, 351 (6274), 681.

13. McDonald, M. R.; Fredericks, F. C.; Margerum, D. W., Characterization of Copper(III)-Tetrapeptide Complexes with Histidine as the Third Residue. Inorg. Chem. 1997, 36 (14), 31193124.

14. Bertz, S. H.; Cope, S.; Murphy, M.; Ogle, C. A.; Taylor, B. J., Rapid Injection NMR in Mechanistic Organocopper Chemistry. Preparation of the Elusive Copper(III) Intermediate. J. Am. Chem. Soc. 2007, 129 (23), 7208-7209.

15. Bertz, S. H.; Cope, S.; Dorton, D.; Murphy, M.; Ogle, C. A., Organocuprate Cross-Coupling: The Central Role of the Copper(III) Intermediate and the Importance of the Copper(I) Precursor. Angew. Chem. Int. Ed. 2007, 46 (37), 7082-7085.

16. Snyder, J. P., Mechanism of Lithium Cuprate Conjugate Addition: Neutral Tetracoordinate $\mathrm{CuI}$ Cuprates as Essential Intermediates. J. Am. Chem. Soc. 1995, 117 (44), 11025-11026. 17. Hu, H.; Snyder, J. P., Organocuprate Conjugate Addition: The Square-Planar "CuIII" Intermediate. J. Am. Chem. Soc. 2007, 129 (23), 7210-7211.

18. Romine, A. M.; Nebra, N.; Konovalov, A. I.; Martin, E.; Benet-Buchholz, J.; Grushin, V. V., Easy Access to the Copper(III) Anion [Cu(CF3)4]-. Angew. Chem. Int. Ed. 2015, 54 (9), 2745-2749. 
19. Anson, F. C.; Collins, T. J.; Richmond, T. G.; Santarsiero, B. D.; Toth, J. E.; Treco, B. G. R. T., Highly stabilized copper(III) complexes. J. Am. Chem. Soc. 1987, 109 (10), 2974-2979.

20. Ribas, X.; Jackson, D. A.; Donnadieu, B.; Mahía, J.; Parella, T.; Xifra, R.; Hedman, B.; Hodgson, K. O.; Llobet, A.; Stack, T. D. P., Aryl C-H Activation by CuII To Form an Organometallic Aryl-CuIII Species: A Novel Twist on Copper Disproportionation. Angew. Chem. Int. Ed. 2002, 41 (16), 2991-2994.

21. Casitas, A.; Canta, M.; Solà, M.; Costas, M.; Ribas, X., Nucleophilic Aryl Fluorination and Aryl Halide Exchange Mediated by a CuI/CuIII Catalytic Cycle. J. Am. Chem. Soc. 2011, 133 (48), 19386-19392.

22. Willert-Porada, M. A.; Burton, D. J.; Baenziger, N. C., Synthesis and X-ray structure of bis(trifluoromethyl)(N,Ndiethyldithiocarbamato)-copper; a remarkably stable perfluoroalkylcopper(III) complex. Chem. Comm. 1989, (21), 16331634.

23. Furuta, H.; Maeda, H.; Osuka, A., Doubly N-Confused Porphyrin: A New Complexing Agent Capable of Stabilizing Higher Oxidation States. J. Am. Chem. Soc. 2000, 122 (5), 803-807.

24. Maeda, H.; Ishikawa, Y.; Matsuda, T.; Osuka, A.; Furuta, $\mathrm{H}$., Control of $\mathrm{Cu}(\mathrm{II})$ and $\mathrm{Cu}(\mathrm{III})$ States in N-Confused Porphyrin by Protonation/Deprotonation at the Peripheral Nitrogen. J. Am. Chem. Soc. 2003, 125 (39), 11822-11823.

25. Maeda, H.; Osuka, A.; Furuta, H., Trans Doubly NConfused Porphyrins: $\mathrm{Cu}$ (III) Complexation and Formation of Rodlike Hydrogen-Bonding Networks. J. Am. Chem. Soc. 2003, 125 (51), 15690-15691.

26. Adinarayana, B.; Thomas, A. P.; Suresh, C. H.; Srinivasan, A., A 6,11,16-Triarylbiphenylcorrole with an adj-CCNN Core: Stabilization of an Organocopper(III) Complex. Angewandte Chemie 2015, 127 (36), 10624-10628.

27. King, A. E.; Huffman, L. M.; Casitas, A.; Costas, M.; Ribas, X.; Stahl, S. S., Copper-Catalyzed Aerobic Oxidative Functionalization of an Arene C-H Bond: Evidence for an ArylCopper(III) Intermediate. J. Am. Chem. Soc. 2010, 132 (34), 1206812073.

28. Liu, L.; Zhu, M.; Yu, H.-T.; Zhang, W.-X.; Xi, Z., Organocopper(III) Spiro Complexes: Synthesis, Structural Characterization, and Redox Transformation. J. Am. Chem. Soc. 2017, 139 (39), 13688-13691.

29. Huffman, L. M.; Stahl, S. S., Carbon-Nitrogen Bond Formation Involving Well-Defined Aryl-Copper(III) Complexes. $J$. Am. Chem. Soc. 2008, 130 (29), 9196-9197.

30. Clark, H. C.; Tsai, J. H., Bonding in fluorinated organometallic compounds. J. Organometallic. Chem. 1967, 7 (3), 515-517.

31. Hall, M. B.; Fenske, R. F., Electronic structure and bonding in methyl- and perfluoromethyl(pentacarbonyl)manganese. Inorg. Chem. 1972, 11 (4), 768-775.

32. Algarra, A. G.; Grushin, V. V.; Macgregor, S. A., Natural Bond Orbital Analysis of the Electronic Structure of $[\mathrm{LnM}(\mathrm{CH} 3)]$ and [LnM(CF3)] Complexes. Organometallics 2012, 31 (4), 1467-1476.

33. Naumann, D.; Roy, T.; Tebbe, K.-F.; Crump, W., Synthesis and Structure of Surprisingly Stable

Tetrakis(trifluoromethyl)cuprate(III) Salts. Angew. Chem. Int. Ed. 1993, 32 (10), 1482-1483.

34. Zhang, S.-L.; Bie, W.-F., Isolation and characterization of copper(iii) trifluoromethyl complexes and reactivity studies of aerobic trifluoromethylation of arylboronic acids. $R S C A d v$. 2016, 6 (75), 70902-70906

35. Zhang, S.-L.; Bie, W.-F., Ligand-dependent formation of ion-pair $\mathrm{CuI} / \mathrm{CuIII}$ trifluoromethyl complexes containing bisphosphines. Dal. Trans. 2016, 45 (44), 17588-17592.

36. Zhang, S.-L.; Xiao, C.; Wan, H.-X., Diverse copper(iii) trifluoromethyl complexes with mono-, bi- and tridentate ligands and their versatile reactivity. Dal. Trans. 2018, 47 (14), 4779-4784. 37. Tan, X. Q.; Liu, Z. L.; Shen, H. G.; Zhang, P.; Zhang, Z. Z.; Li, C. Z., Silver-Catalyzed Decarboxylative Trifluoromethylation of Aliphatic Carboxylic Acids. J. Am. Chem. Soc. 2017, 139 (36), 12430-12433.
38. Muller, K.; Faeh, C.; Diederich, F, Fluorine in pharmaceuticals: Looking beyond intuition. Science 2007, 317 (5846), 1881-1886.

39. O'Hagan, D., Understanding organofluorine chemistry. An introduction to the C-F bond. Chem. Soc. Rev. 2008, 37 (2), 308-319.

40. Liu, T. F.; Shen, Q. L., Copper-Catalyzed

Trifluoromethylation of Aryl and Vinyl Boronic Acids with An Electrophilic Trifluoromethylating Reagent. Org. Lett. 2011, 13 (9), 2342-2345.

41. Oishi, M.; Kondo, H.; Amii, H., Aromatic

trifluoromethylation catalytic in copper. Chem Commun. 2009, (14), 1909-1911.

42. Knauber, T.; Arikan, F.; Roschenthaler, G. V.; Goossen, L. J., Copper-Catalyzed Trifluoromethylation of Aryl Iodides with Potassium (Trifluoromethyl)trimethoxyborate. Chem-Eur. J. 2011, 17 (9), 2689-2697.

43. Morimoto, H.; Tsubogo, T.; Litvinas, N. D.; Hartwig, J. F., A Broadly Applicable Copper Reagent for Trifluoromethylations and Perfluoroalkylations of Aryl Iodides and Bromides. Angew. Chem. Int. Ed. 2011, 50 (16), 3793-3798.

44. Zhang, C. P.; Wang, Z. L.; Chen, Q. Y.; Zhang, C. T.; Gu, Y. C.; Xiao, J. C., Copper-Mediated Trifluoromethylation of Heteroaromatic Compounds by Trifluoromethyl Sulfonium Salts. Angew. Chem. Int. Ed. 2011, 50 (8), 1896-1900.

45. Dubinina, G. G.; Furutachi, H.; Vicic, D. A., Active trifluoromethylating agents from well-defined copper(I)-CF(3) complexes. J. Am. Chem. Soc. 2008, 130 (27), 8600-+.

46. Senecal, T. D.; Parsons, A. T.; Buchwald, S. L., Room Temperature Aryl Trifluoromethylation via Copper-Mediated Oxidative Cross-Coupling. J. Org. Chem. 2011, 76 (4), 1174-1176. 47. Dai, J. J.; Fang, C.; Xiao, B.; Yi, J.; Xu, J.; Liu, Z. J.; Lu, X.; Liu, L.; Fu, Y., Copper-Promoted Sandmeyer

Trifluoromethylation Reaction. J. Am. Chem. Soc. 2013, 135 (23), 8436-8439.

48. Xu, X. L.; Chen, H. H.; He, J. B.; Xu, H. J., CopperCatalysed Decarboxylative Trifluoromethylation of beta-Ketoacids. Chinese J. Chem. 2017, 35 (11), 1665-1668.

49. $\quad$ Paeth, M.; Carson, W.; Luo, J.-H.; Tierney, D.; Cao, Z.; Cheng, M.-J.; Liu, W., Copper-Mediated Trifluoromethylation of Benzylic Csp3-H Bonds. Chem. Eur. J. 2018, 24 (45), 11559-11563. 50. Konovalov, A. I.; Lishchynskyi, A.; Grushin, V. V., Mechanism of Trifluoromethylation of Aryl Halides with CuCF3 and the Ortho Effect. J. Am. Chem. Soc. 2014, 136 (38), 13410-13425.

51. Guo, S.; AbuSalim, D. I.; Cook, S. P., Aqueous Benzylic C-H Trifluoromethylation for Late-Stage Functionalization. J. Am. Chem. Soc. 2018, 140 (39), 12378-12382.

52. Ball, N. D.; Kampf, J. W.; Sanford, M. S., Aryl-CF3 BondForming Reductive Elimination from Palladium(IV). J. Am. Chem. Soc. 2010, 132 (9), 2878-+.

53. Grushin, V. V.; Marshall, W. J., Facile Ar-CF3 Bond Formation at Pd. Strikingly Different Outcomes of Reductive Elimination from [(Ph3P)2Pd(CF3)Ph] and [(Xantphos) $\mathrm{Pd}(\mathrm{CF} 3) \mathrm{Ph}]$. J. Am. Chem. Soc. 2006, 128 (39), 12644-12645.

54. Bour, J. R.; Camasso, N. M.; Meucci, E. A.; Kampf, J. W.; Canty, A. J.; Sanford, M. S., Carbon-Carbon Bond-Forming Reductive Elimination from Isolated Nickel(III) Complexes. J. Am. Chem. Soc. 2016, 138 (49), 16105-16111.

55. Winston, M. S.; Wolf, W. J.; Toste, F. D., Photoinitiated Oxidative Addition of CF3I to Gold(I) and Facile Aryl-CF3

Reductive Elimination. J. Am. Chem. Soc. 2014, 136 (21), 7777-7782. 56. Levin, M. D.; Chen, T. Q.; Neubig, M. E.; Hong, C. M.; Theulier, C. A.; Kobylianskii, I. J.; Janabi, M.; O'Neil, J. P.; Toste, F. D., A catalytic fluoride-rebound mechanism for $\mathrm{C}(\mathrm{sp}(3))-\mathrm{CF} 3$ bond formation. Science 2017, 356 (6344), 1272-1275.

57. Cho, E. J.; Senecal, T. D.; Kinzel, T.; Zhang, Y.; Watson, D. A.; Buchwald, S. L., The Palladium-Catalyzed

Trifluoromethylation of Aryl Chlorides. Science 2010, 328 (5986), $1679-1681$

58. Shen, H.; Liu, Z.; Zhang, P.; Tan, X.; Zhang, Z.; Li, C., Trifluoromethylation of Alkyl Radicals in Aqueous Solution. J. Am. Chem. Soc. 2017, 139 (29), 9843-9846. 
59. Chen, Y.; Ma, G.; Gong, H., Copper-Catalyzed Reductive Trifluoromethylation of Alkyl Iodides with Togni's Reagent. Org. Lett. 2018, 20 (15), 4677-4680.

60 Low, J. J.; Goddard, W. A., Theoretical studies of oxidative addition and reductive elimination. 3. Carbon-hydrogen and carboncarbon reductive coupling from palladium and platinum bis(phosphine) complexes. J. Am. Chem. Soc. 1986, 108 (20), 61156128.

61. Reed, A. E.; Curtiss, L. A.; Weinhold, F., Intermolecular Interactions from a Natural Bond Orbital, Donor-Acceptor Viewpoint. Chem. Rev. 1988, 88 (6), 899-926. 
$\mathrm{Csp}^{3}-\mathrm{Csp}^{3}$ bond forming reductive elimination from well-defined $\mathrm{Cu}^{\prime \prime \prime}$

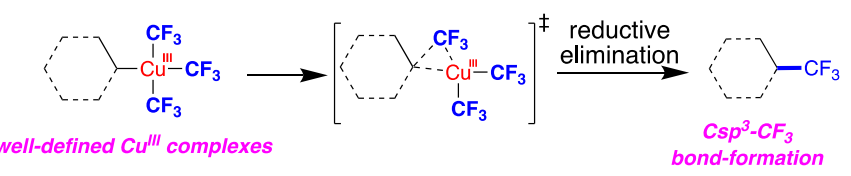

- Highly efficient method to synthesize alkyl-Culll complexes

- $\mathrm{Csp}^{3}-\mathrm{Csp}^{3}$ bond-forming reductive elimination from $\mathrm{Cu}^{\mathrm{III}}$

- Computational insights into the elementary reductive elimination step 